\title{
Destruction of Toluene by the Combination of High Frequency Discharge Electrodeless Lamp and Manganese Oxide-Impregnated Granular Activated Carbon Catalyst
}

\author{
Jianhui Xu, ${ }^{1}$ Chaolin Li, ${ }^{1}$ Qian Zhang, ${ }^{1,2}$ Di He, ${ }^{3}$ Peng Liu, ${ }^{1}$ and Yong Ren ${ }^{1}$ \\ ${ }^{1}$ Environmental Science \& Engineering Research Center, Harbin Institute of Technology, Shenzhen Graduate School, \\ Shenzhen 518055, China \\ ${ }^{2}$ Postdoctoral Innovation Practice Base, Bureau of Public Works of Longgang Shenzhen Municipality, Shenzhen, \\ Guangdong 518172, China \\ ${ }^{3}$ School of Civil and Environmental Engineering, University of New South Wales, Sydney, NSW 2052, Australia
}

Correspondence should be addressed to Chaolin Li; lichaolinhit@gmail.com

Received 28 June 2014; Revised 21 August 2014; Accepted 8 September 2014; Published 13 October 2014

Academic Editor: Hongtao Yu

Copyright ( 92014 Jianhui Xu et al. This is an open access article distributed under the Creative Commons Attribution License, which permits unrestricted use, distribution, and reproduction in any medium, provided the original work is properly cited.

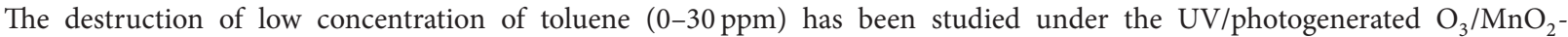
impregnated granular activated carbon $\left(\mathrm{MnO}_{2}\right.$-impregnated $\left.\mathrm{GAC}\right)$ process by the combination of self-made high frequency discharge electrodeless lamp (HFDEL) with $\mathrm{MnO}_{2}$-impregnated GAC catalyst. Experimental results showed that the initial toluene concentration can strongly affect the concentration of photogenerated $\mathrm{O}_{3}$ from HFDEL and the efficiency and mass rate of destruction of toluene via HFDEL/ $\mathrm{MnO}_{2}$-impregnated GAC system. Active oxygen and hydroxyl radicals generated from $\mathrm{HFDEL} / \mathrm{MnO}_{2}$-impregnated GAC system played a key role in the decomposition of toluene process and the intermediates formed by photolysis are more prone to be mineralized by the subsequent $\mathrm{MnO}_{2}$-impregnated $\mathrm{GAC}$ catalyst compared to the original toluene, resulting in synergistic mineralization of toluene by $\mathrm{HFDEL} / \mathrm{MnO}_{2}$-impregnated GAC system. The role of $\mathrm{MnO}_{2}$-impregnated GAC catalyst is not only to eliminate the residual $\mathrm{O}_{3}$ completely but also to enhance the decomposition and mineralization of toluene.

\section{Introduction}

Volatile organic compounds (VOCs) as widespread air pollutants can be found in both outdoor and indoor environments. The majority of VOCs originate from the exhausts of motor vehicle and solvent utilization and VOCs from the former case can react with $\mathrm{NO}_{x}$ to form tropospheric $\mathrm{O}_{3}$ which results in smog in urban air [1]. Exposure to VOCs might cause toxic effects on central nervous system and internal organs, and the related symptoms, such as headache, respiratory tract irritation, dizziness, and nausea, are known as the sick building syndrome (SBS) [2]. For high concentration (several hundreds of ppm) of VOCs emission sources, catalytic incineration and combustion $\left(200-900^{\circ} \mathrm{C}\right)$ have been well developed and successfully operated but are not cost-effective for low concentration of VOCs [3]. Among those available potential air-cleaning technologies for contamination of lower concentration of VOCs, photocatalytic oxidation (PCO) has caused extensive concern recently, but the problems of the poisoning or deactivation of photocatalyst caused by accumulation of organic products on the surface of catalyst have not been well solved [4, 5], which may render PCO as a technology for controlling contaminations of low concentration of VOCs inefficiently and uneconomically.

High frequency (HF) discharge electrodeless lamp (HFDEL), a typical UV light source, has been invented over 100 years and started to apply into the photolysis of organic compounds in solution and the irradiation of gases since 1970s [6]. Due to the leakage of electromagnetic radiation and ozone, however, the application of HFDEL became restricted afterwards. Unlike the conventional lamps energized by the electric field between the electrodes, the principle of HFDELs is that the gas or materials in the lamp are excited by $\mathrm{HF}$ 
electromagnetic field to form stable UV-emitting discharge plasma. Such unique discharge pattern endows the HFDELs with lots of advantages compared to the conventional UV lamps (i.e., low pressure mercury lamps), including long lifetime of UV output, high UV/vacuum UV (VUV) radiant power, VUV-mediated generation of $\mathrm{O}_{3}$ in conjunction with UV to create hydroxyl radicals $\left(\mathrm{HO}^{\circ}\right)$, and adaptable lamp shapes. Compared to microwave discharge electrodeless lamps (MDELs), HFDELs possess higher energy conversion efficiency, have no need for resonant cavity, and overcome the short lifetime of magnetron equipped on MDELs. Employing mercury MDELs to water sterilization $[7,8]$ and photodissociation of organic pollutants in aqueous solution [9-12] have been studied extensively in the past few years, as mercury is the most readily to be excited, and even a domestic microwave oven may act as the microwave power supply reactor [13]. However, little has been done on the photolysis of VOCs using MDELs as the UV light source probably due to practical limitations in reactor design and operation for the treatment of gas pollutants [14]. Recently, we have investigated the photolysis of $\mathrm{H}_{2} \mathrm{~S}$ using HFDEL showing much higher removal efficiency compared to MDELs, gained some insights into the possible mechanisms for photolysis, and confirmed the feasibility of application of HFDEL into the decomposition of air pollutants [15]. To further extend the application of HFDEL, the photolysis of VOCs by HFDEL has been investigated in this study. To cope with electromagnetic radiation generated from HFDEL, stainless steel reactors have been applied in this study to minimize the negative effects of electromagnetic wave on human bodies. Meanwhile, the stainless steel reactor is also beneficial in the reflection of UV light and resistant to corrosion of corrosive gas.

Although photogenerated $\mathrm{O}_{3}$ by HFDEL can induce advanced oxidation processes (AOPs) such as $\mathrm{UV} / \mathrm{O}_{3}$ to produce $\mathrm{HO}^{\circ}$ for effectively decomposing VOCs, excess $\mathrm{O}_{3}$, as an air pollutant, in the effluent gas stream should be reduced to a safe level. Therefore, a reactor containing an $\mathrm{O}_{3}$-decomposition catalyst (ODC) needs to be set up following the photoreactor to treat excess $\mathrm{O}_{3}$ in the effluent gas stream. The $\mathrm{O}_{3}$ /granular activated carbon (GAC) method is relatively common in which the GAC performs dual roles: adsorption of residual $\mathrm{O}_{3}$ and VOCs (their organic products) and decomposition of $\mathrm{O}_{3}$ over the surface to yield $\mathrm{HO}^{\circ}$, which in turn are able to quickly mineralize VOCs and their organic products adsorbed on the surface of GAC and/or in gas phase [16]. To further enhance the $\mathrm{O}_{3}$ decomposition and generation of $\mathrm{HO}^{\circ}$ for mineralization of VOCs and their organic products, the impregnation of $\mathrm{MnO}_{2}$ on GAC has been applied in this study as $\mathrm{MnO}_{2}$ shows an excellent simultaneous elimination of VOCs and $\mathrm{O}_{3}$ [17]. In addition to the elimination of excess $\mathrm{O}_{3}$ and enhanced removal of VOCs, the combination of HFDEL and ODC may also have the following advantages: (i) the photolysis of VOCs results in the partial mineralization of VOCs, which may reduce the accumulation of organic intermediates on the surface of ODC and extend the lifetime of ODC, (ii) photogenerated $\mathrm{O}_{3}$ may have a positive effect on the regeneration of ODC considering that $\mathrm{O}_{3}$ photogenerated from HFEDL can regenerate the photocatalyst [18], and (iii) the organic intermediates of photolysis may be more subject to be mineralized by $\mathrm{MnO}_{2}-$ impregnated $/ \mathrm{O}_{3}$ compared to the original VOCs.

In this study, a preliminary study on the removal of VOCs with the combination of HFDEL and $\mathrm{MnO}_{2}$-impregnated GAC was investigated. Filled with binary mixtures of $\mathrm{Hg}-\mathrm{Ar}$, HFDEL was found to emit intense atomic lines of mercury in both UV and VUV region (mainly atomic $\mathrm{Hg}$ emission lines at $185 \mathrm{~nm}\left(6 \mathrm{~s} 6 \mathrm{p}\left({ }^{1} \mathrm{P}_{1}\right)-6 \mathrm{~s} 6 \mathrm{p}\left({ }^{1} \mathrm{~S}_{0}\right)\right)$ and $253.7 \mathrm{~nm}\left(6^{2} \mathrm{P}_{1}-\right.$ $6^{2} \mathrm{~S}_{0}$ ) [15] and $\mathrm{MnO}_{2}$-impregnated GAC was confirmed to decompose $\mathrm{O}_{3}$ and induce the formation of $\mathrm{O}^{\circ}$ and $\mathrm{HO}^{\circ}$ following the exposure to $\mathrm{O}_{3}$. A relatively low concentration level of toluene as the target VOC, in the range of 0 $30 \mathrm{ppm}$, was selected for this work, in the consideration of ubiquitousness of indoor and outdoor environments. The performances of removal and mineralization of toluene were examined under different conditions with photolysis by HFDEL, $\mathrm{MnO}_{2}$-impregnated GAC-mediated catalyzed ozonation, and the combination of HFDEL and $\mathrm{MnO}_{2}-$ impregnated GAC. The analysis of intermediates and possible mechanisms for photolysis and catalyzed ozonation were also evaluated in this study.

\section{Materials and Methods}

2.1. HFDEL. HFDEL consisted of an HF power supply and electrodeless lamps. The HF power supply was operated to produce a current with a fixed frequency of $2.45 \mathrm{MHz}$, which was transmitted to a coupling fixture to generate an HF electromagnetic field. The mercury atoms were excited by the HF electromagnetic field followed by returning to ground state to emit UV light $[13,19]$. The working power for HFDEL was $80 \mathrm{~W}$ which was sufficient to ignite the quartz lamp. The electrodeless lamps were made of quartz bulb with the height of $15 \mathrm{~cm}$ (the volume is $\sim 550 \mathrm{~mL}$ ).

2.2. Characterization of HFDEL. The emission spectrum of UV radiation emitted by HFDEL was detected by an Acton VM-505 VUV monochromator. The stability of light intensity of HFDEL at $253.7 \mathrm{~nm}$ was monitored at the outflow of the photolysis reactor by an irradiatometer (TN-2254, Taiwan Taina Instrument) while the distribution of light intensity at $253.7 \mathrm{~nm}$ as a function of the distance to the bottom center of the lamp was measured by the same irradiatometer. More details have been shown in Supplementary Material available online at http://dx.doi.org/10.1155/2014/365862 (SM) (Figures SM1-3).

2.3. $\mathrm{MnO}_{2}$-Impregnated GAC. Wood-based GAC (cylinder shape with a diameter of $4 \mathrm{~cm}$ ) was selected as supporting material in this study (Calgon Carbon Corporation in Tianjin, China). Firstly, GAC was acid-treated in a $5 \%$ solution of hydrochloric acid for $6 \mathrm{~h}$ to reduce ash content, washed with Milli-Q water (MQ) repeatedly to reach neutrality, and dried at $105^{\circ} \mathrm{C}$ for $24 \mathrm{~h}$. Then $500 \mathrm{~g}$ GAC and certain amounts of $\mathrm{Mn}\left(\mathrm{NO}_{3}\right)_{2}$ were mixed with $2 \mathrm{~L}$ MQ and constantly shaken for 24 hours at $25^{\circ} \mathrm{C}$ for the preparation of $\mathrm{MnO}_{2}$-impregnated GAC with different mass loading of $\mathrm{MnO}_{2}$ from 0 to $10 \%$. The concentration of $\mathrm{Mn}^{2+}$ 


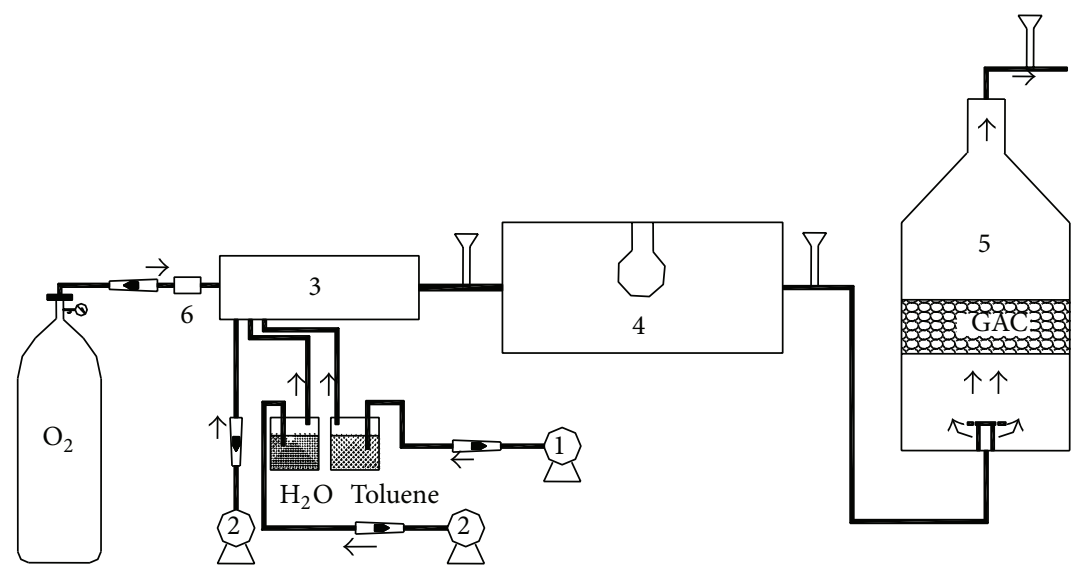

(1) Continuous flow toluene gas generation system

(2) Experimental parameter control system

(3) Mixing tube

(4) HFDEL

(5) $\mathrm{MnO}_{2}$-impregnated GAC system

(6) Ozone generator

FIgURE 1: The sketch of experimental setup of the combination of HFDEL with $\mathrm{MnO}_{2}$-impregnated GAC system.

in the supernatant was characterized by inductively coupled plasma-optical emission spectrometry (ICP-OES) (Varian AX, Varian) confirming $\sim 100 \% \mathrm{Mn}^{2+}$ has been adsorbed on GAC. Afterwards, the solids were filtrated and dried overnight at $105^{\circ} \mathrm{C}$ for $12 \mathrm{~h}$ in an air oven and calcinated at $450^{\circ} \mathrm{C}$ in muffle furnace for $6 \mathrm{~h}$. Mineralogy of the $\mathrm{MnO}_{2}$ was characterized by X-ray diffraction (Rigaku D/MAX 2500). The surface morphology of $\mathrm{MnO}_{2}$-impregnated GAC was obtained by scanning electron microscope (Hitachi S-4700).

2.4. Experimental Setup. The experimental setup designed for the evaluation of toluene removal efficiency by HFDEL/ $\mathrm{MnO}_{2}$-impregnated GAC is shown in Figure 1. The system consisted of an experimental parameter control system, a continuous flow gas generation system, HFDEL stainless steel reactor, and $\mathrm{MnO}_{2}$-impregnated $\mathrm{GAC}$ system. The toluene gas was pumped via the bubbling of air into the toluene solution (1) and the humidity was adjusted to $74.1 \%$ through the experimental parameter control system (2). The mixture of toluene was transferred through a mixing tube (3) before introducing into the photolysis area (4), which is followed by $\mathrm{MnO}_{2}$-impregnated GAC system (5). The ozone generator (6) was only applied to investigate the effect of $\mathrm{O}_{3} / \mathrm{MnO}_{2}$ impregnated GAC on the removal of toluene. The gas stream passed through the reactor for $15 \mathrm{~min}$ to allow the system to reach the steady state. Power was then applied to inspire the lamp for another $10 \mathrm{~min}$ to make sure the steady state of light intensity had been achieved before the measurement of concentration of toluene in the gas stream. The initial toluene concentration ranged from 0 to $30 \mathrm{ppm}$. All the experiments were carried out at fixed gas flow rate of $4 \mathrm{~m}^{3} \mathrm{~h}^{-1}$ at room temperature $\left(25 \pm 2^{\circ} \mathrm{C}\right)$.

2.5. Chemical Analysis. The concentration of toluene and its final product $\mathrm{CO}_{2}$ in the air stream was analyzed by a gas chromatograph (GC, Thermo Finnigan) equipped with flame ionization detector (FID), respectively. The concentration of $\mathrm{O}_{3}$ was monitored spectrophotometrically at $254 \mathrm{~nm}$ where $\mathrm{O}_{3}$ possesses a molar absorptivity of $3292 \pm 70 \mathrm{M}^{-1} \mathrm{~cm}^{-1}$ [20]. The gaseous intermediates in the outlet gas were collected by an absorption bottle filled with HPLC grade methanol (Dima Technology, USA) for $1 \mathrm{~h}$ after the reaction reached equilibrium. The solution was analyzed by GC (Agilent 6890A)-MSD (Agilent 5975C with Triple-Axis Detector). The carrier gas was ultrahigh purity helium at a constant flow rate of $1 \mathrm{~mL} \mathrm{~min}^{-1}$. The injector and detector temperatures were set at 230 and $270^{\circ} \mathrm{C}$, respectively. The GC column was DB-5 (30 m $\times 0.25 \mathrm{~mm} \times 0.25 \mathrm{~mm}$, Agilent technology). The temperature of the $\mathrm{GC}$ oven was initially set at $80^{\circ} \mathrm{C}$ for $1 \mathrm{~min}$ and then raised at $5^{\circ} \mathrm{C} \mathrm{min}^{-1}$ to $250^{\circ} \mathrm{C}$ for $3 \mathrm{~min}$ with a subsequent increase to a final $300^{\circ} \mathrm{C}$ at a rate of $10^{\circ} \mathrm{C} \mathrm{min} \mathrm{m}^{-1}$ for $5 \mathrm{~min}$. $1.0 \mu \mathrm{L}$ of sample was injected in the splitless mode.

\section{Results}

3.1. Generation of $\mathrm{O}_{3}$. As photogenerated $\mathrm{O}_{3}$ can induce AOPs including $\mathrm{UV} / \mathrm{O}_{3}$ and $\mathrm{MnO}_{2}$-impregnated $\mathrm{GAC} / \mathrm{O}_{3}$ to create $\mathrm{HO}^{\circ}$ for effective decomposition of toluene, the concentration of generated $\mathrm{O}_{3}$ as a function of inlet toluene concentration was investigated. Figure 2 shows that the concentration of photogenerated $\mathrm{O}_{3}$ decreased from 130 to $41 \mathrm{ppm}$ with an increase in the inlet toluene concentration from 0 to $30 \mathrm{ppm}$. The possible pathway of $\mathrm{O}_{3}$ formation during the UV photolysis process is as follows (see (1)-(3)):

$$
\begin{gathered}
\mathrm{O}_{2}+h v(\lambda<200 \mathrm{~nm}) \longrightarrow \mathrm{O}^{\bullet}+\mathrm{O}^{\bullet} \\
\mathrm{H}_{2} \mathrm{O}+\mathrm{O}^{\bullet} \longrightarrow \mathrm{HO}^{\bullet}+\mathrm{HO}^{\bullet} \\
\mathrm{O}_{2}+\mathrm{O}^{\bullet} \longrightarrow \mathrm{O}_{3}
\end{gathered}
$$




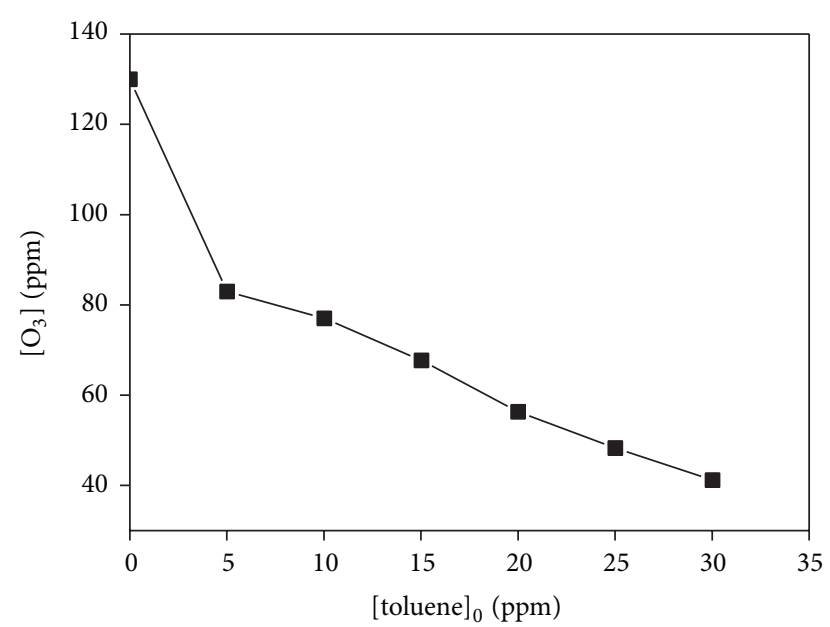

Figure 2: Photogenerated $\mathrm{O}_{3}$ concentration as a function of inlet toluene concentration.

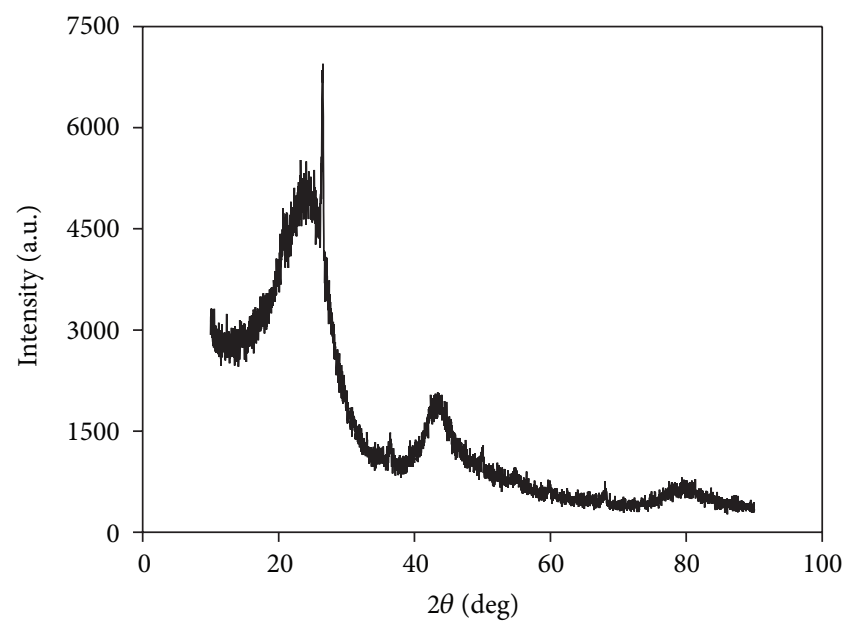

FIGURE 3: XRD pattern of $\mathrm{MnO}_{2}$-impregnated GAC.

$\mathrm{O}^{\bullet}$ is commonly regarded as the main oxidant in the catalytic ozonation [21]. The primary pathway of toluene oxidation by $\mathrm{O}^{\bullet}$ is the abstraction of hydrogen atoms from the methyl group, directly resulting in the production of benzyl alcohol or/and benzaldehyde, which were further attacked by an $\mathrm{O}^{*}$ leading to benzoic acid or the direct opening of the aromatic ring followed by mineralization of intermediates by $\mathrm{O}^{\bullet}$ [22]. With an increase in the inlet concentration of toluene, therefore, the consumption of $\mathrm{O}^{*}$ by toluene increases, which may result in a decrease in the generation of $\mathrm{O}_{3}$ during photolysis process (see (3)).

3.2. Optimization of $\mathrm{MnO}_{2}$-Impregnated GAC. In addition to the elimination of excess $\mathrm{O}_{3}, \mathrm{MnO}_{2}$-impregnated GAC was also applied to enhance the removal of toluene through the catalyzed-ozonation process. The XRD pattern of $\mathrm{MnO}_{2}$ impregnated GAC is shown in Figure 3. Besides two basic diffraction peaks $\left(2 \theta=24^{\circ}\right.$ and $\left.43^{\circ}\right)$, there is a sharp and intense peak at about $2 \theta=26^{\circ}$, which is identified with the typical spectrum of $\beta-\mathrm{MnO}_{2}$ phase [23], the most stable

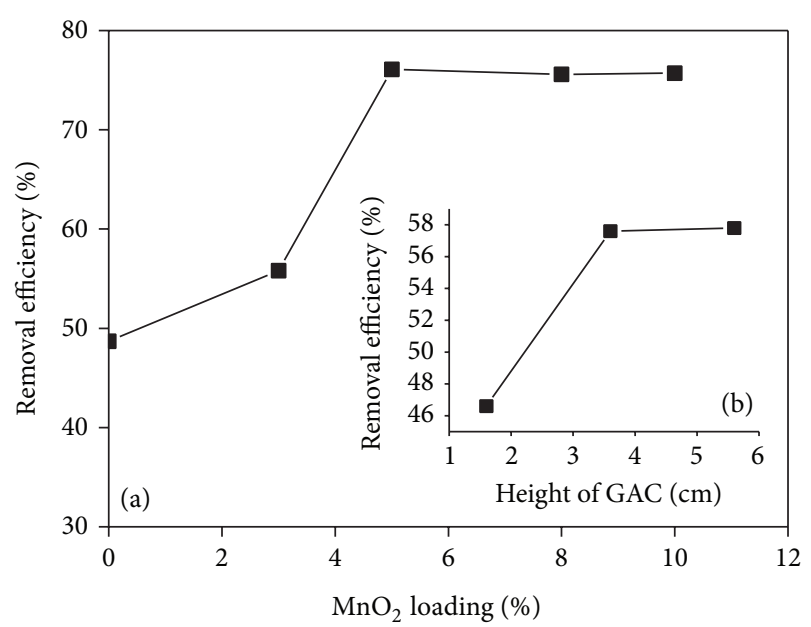

FIgURE 4: Removal efficiency of toluene as a function of (a) $\mathrm{MnO}_{2}$ loading and (b) height of GAC during the $\mathrm{O}_{3} / \mathrm{MnO}_{2}$ impregnated GAC process. Experimental conditions: (a) $\left[\mathrm{O}_{3}\right]_{0}=$ $40 \mathrm{ppm}$; [toluene $]_{0}=9 \mathrm{ppm}$; the height of $\mathrm{GAC}=1.6 \mathrm{~cm}$; (b) $\left[\mathrm{O}_{3}\right]_{0}=$ $40 \mathrm{ppm}$; [toluene $]_{0}=20 \mathrm{ppm}$; the loading of $\mathrm{MnO}_{2}=5 \%$.

structure in a variety of $\mathrm{Mn}$ (IV) oxides structural forms at low temperatures [23]. In addition, significant instrumental noises indicate that $\mathrm{MnO}_{2}$ impregnated on the surface is amorphous in structure. Figure 4(a) shows the removal efficiency of toluene as a function of the loading of $\mathrm{MnO}_{2}$ impregnated on GAC $(0-10 \%)$, where the inlet concentrations of toluene and $\mathrm{O}_{3}$ are 9 and $40 \mathrm{ppm}$, respectively, and the depth of GAC is fixed at $1.6 \mathrm{~cm}$. To evaluate the "real" decomposition of toluene by $\mathrm{MnO}_{2}$-impregnated $\mathrm{GAC} / \mathrm{O}_{3}$, all adsorption sites of $\mathrm{MnO}_{2}$-impregnated $\mathrm{GAC}$ were saturated with toluene followed by the introduction of $\mathrm{O}_{3}$ (the breakthrough curve for the adsorption of toluene by $\mathrm{MnO}_{2}-$ impregnated GAC has been shown as in Figure SM-4). Since it has been confirmed previously that molecular $\mathrm{O}_{3}$ reacts very slowly with toluene $\left(1.4 \mathrm{M}^{-1} \mathrm{~s}^{-1}\right)$ [24], the observed reduction of toluene by $\mathrm{MnO}_{2}$-impregnated $\mathrm{GAC} / \mathrm{O}_{3}$ in Figure 4 could be largely the result of a partial formation of $\mathrm{HO}^{\bullet}$ and $\mathrm{O}^{*}$ (the rate constants for the reaction of toluene with $\mathrm{HO}^{\circ}$ and $\mathrm{O}^{\circ}$ are $3.0 \times 10^{9}[25]$ and $2.1 \times 10^{9} \mathrm{M}^{-1} \mathrm{~s}^{-1}$ [26], resp.), which is consistent with other reports that the decomposition of toluene and its intermediates mainly result from the presence of $\mathrm{HO}^{\circ}$ and $\mathrm{O}^{\circ}$ produced during $\mathrm{O}_{3}$ decomposition over $\mathrm{MnO}_{2}$ layer $[17,27,28]$. With an increase in the loading of $\mathrm{MnO}_{2}$ from 0 to $5 \%$, the impregnation of $\mathrm{MnO}_{2}$ on GAC indeed enhanced the decomposition of toluene from 49 to $76 \%$ while the degradation of toluene remained unchanged $(76 \%)$ with a further increase in the loading of $\mathrm{MnO}_{2}$ from 5 to $10 \%$, which could be attributed to (i) the complete consumption of $\mathrm{O}_{3}$ which halts the initiation of $\mathrm{HO}^{\circ}$ and $\mathrm{O}^{\circ}$ formation and/or (ii) overloading of $\mathrm{MnO}_{2}$ which could block the access of $\mathrm{O}_{3}$ to surface sites within the pores of GAC, as shown in Figure 5. Therefore, the optimal loading of $\mathrm{MnO}_{2}$ is selected as $5 \%$ when the inlet concentration of $\mathrm{O}_{3}$ is $40 \mathrm{ppm}$.

Similarly, the effect of depth of GAC layer on the decomposition of toluene was also investigated. The $\mathrm{MnO}_{2}-(5 \%)$ 


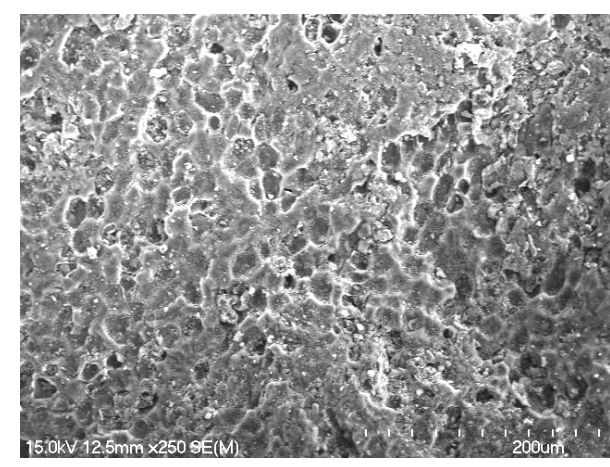

(a)

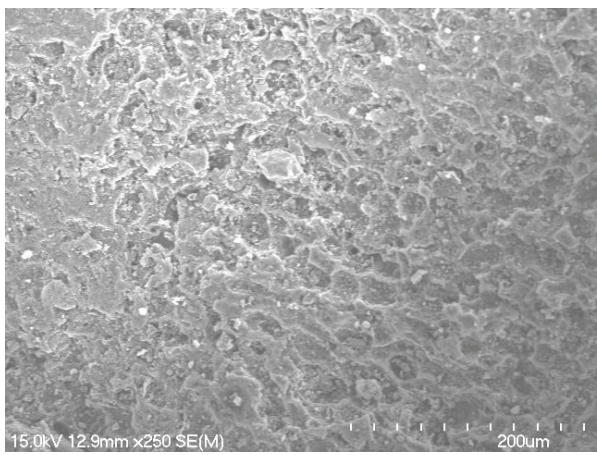

(c)

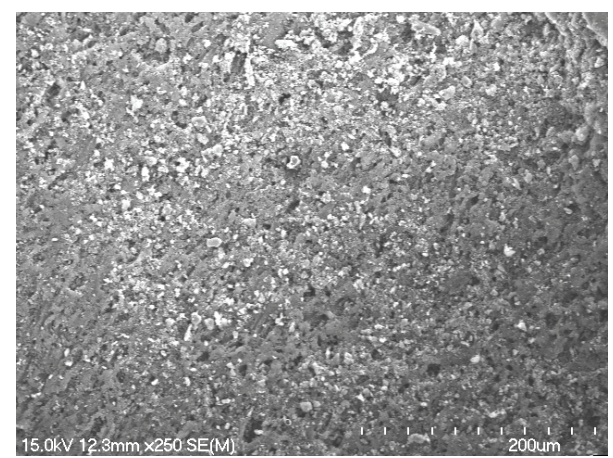

(b)

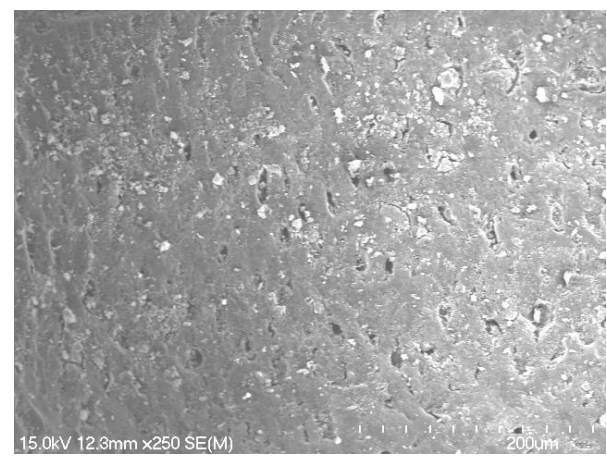

(d)

Figure 5: SEM images of $\mathrm{MnO}_{2}$-impregnated GAC with the different loading of $\mathrm{MnO}_{2}$ (a) 0\%; (b) 3\%; (c) $5 \%$; (d) $10 \%$.

impregnated GACs with different layer depths were saturated with toluene followed by the introduction of $40 \mathrm{ppm} \mathrm{O}_{3}$ and 20 ppm toluene, respectively. Figure 4(b) demonstrates that, with an increase in the depth of GAC layer from 1.6 to $3.6 \mathrm{~cm}$, the decomposition of toluene increased from 47 to $58 \%$ while a further increase in the depth of GAC layer from 3.6 to $5.6 \mathrm{~cm}$ did not result in a further removal of toluene, which could be attributed to the complete elimination of $\mathrm{O}_{3}$ by $\mathrm{MnO}_{2}$-impregnated GACs. As the photogenerated $\mathrm{O}_{3}$ increased from 41 to $130 \mathrm{ppm}$ with a decrease in the inlet toluene concentration from 30 to $0 \mathrm{ppm}$, the ODC system filled with $\mathrm{MnO}_{2}$-impregnated GACs must be capable of removing $130 \mathrm{ppm} \mathrm{O}_{3}$ completely. No detection of $\mathrm{O}_{3}$ in the effluent gas stream has been confirmed when the loading of $\mathrm{MnO}_{2}$ is $5 \%$ and the depth of GAC layer is $3.6 \mathrm{~cm}$. As the inlet $\mathrm{O}_{3}$ concentration varies with the initial concentration of toluene, it might be unrealistic to optimize the loading of $\mathrm{MnO}_{2}$ and depth of GAC for each concentration of toluene. For consistency, therefore, the loading of $\mathrm{MnO}_{2}$ and the depth of GAC layer were selected as $5 \%$ and $4.0 \mathrm{~cm}$ in the following experiments, respectively.

3.3. Decomposition and Mineralization of Toluene. Figures 6(a) and 7(a) show the removal and mineralization efficiency of toluene as a function of inlet toluene concentration from 5 to $30 \mathrm{ppm}$, respectively. The efficiencies of toluene decomposition by HFDEL, $\mathrm{MnO}_{2}$-impregnated $\mathrm{GAC} / \mathrm{O}_{3}$, and HFDEL/ $/ \mathrm{MnO}_{2}$-impregnated GAC were observed (Figure 6(a)) to decrease from 90 to $46 \%, 94$ to $30 \%$, and
100 to $55 \%$, respectively, while the efficiencies of toluene mineralization by $\mathrm{HFDEL}, \mathrm{MnO}_{2}$-impregnated $\mathrm{GAC} / \mathrm{O}_{3}$, and $\mathrm{HFDEL} / \mathrm{MnO}_{2}$-impregnated GAC (Figure 7(a)) decreased from 74 to $12 \%, 86$ to $7 \%$, and 100 to $23 \%$, respectively, as the inlet toluene concentration increases from 5 to $30 \mathrm{ppm}$. It is noted that the inlet $\mathrm{O}_{3}$ concentration in the case of $\mathrm{MnO}_{2}$-impregnated $\mathrm{GAC} / \mathrm{O}_{3}$ is consistent with the concentration of photogenerated $\mathrm{O}_{3}$ from HFDEL as a function of inlet toluene concentration. Since the number and energy of photons and active radicals in the reaction area did not change at a fixed input $\mathrm{HF}$ power and a constant dosage of catalyst, with constant gas flow rate, unit toluene obtains less energy as inlet toluene concentration increases, which results in relatively lower removal and mineralization efficiencies of higher concentration of inlet toluene. The $\mathrm{HFDEL} / \mathrm{MnO}_{2}$-impregnated $\mathrm{GAC}$ possesses higher removal efficiency compared to HFDEL only, which implies the combination of HFDEL with $\mathrm{MnO}_{2}$-impregnated GAC indeed enhances the removal of toluene. More importantly, the synergistic effects of the mineralization of toluene by $\mathrm{HFDEL} / \mathrm{MnO}_{2}$-impregnated GAC were found in Figure $7(\mathrm{a})$ in which the mineralization efficiency of toluene by $\mathrm{HFDEL} / \mathrm{MnO}_{2}$-impregnated $\mathrm{GAC}$ is higher than the summation of the efficiency by HFDEL only and $\mathrm{MnO}_{2}$-impregnated $\mathrm{GAC} / \mathrm{O}_{3}$ under the circumstances of the inlet toluene concentration between 20 and $30 \mathrm{ppm}$, suggesting the photolysis of toluene by HFDEL enhances the subsequent mineralization of toluene by $\mathrm{MnO}_{2}$-impregnated $\mathrm{GAC} / \mathrm{O}_{3}$. These synergistic effects could be attributed to 


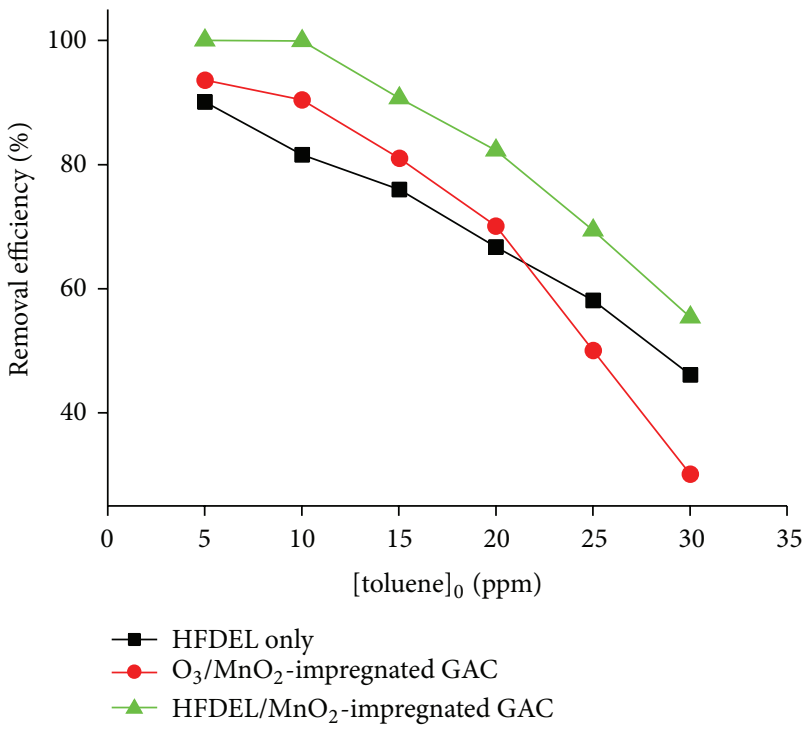

(a)

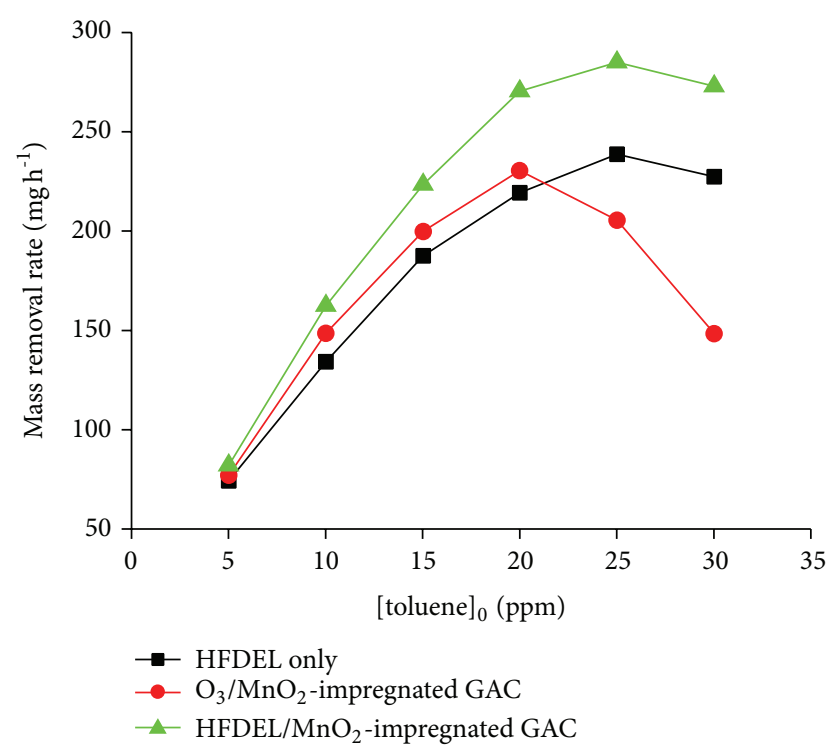

(b)

Figure 6: (a) Removal efficiency and (b) mass removal rate of toluene as a function of inlet toluene concentration by $\mathrm{HFDEL}$ only, $\mathrm{O}_{3} / \mathrm{MnO}_{2}$ impregnated GAC, and HFDEL/MnO 2 -impregnated GAC, respectively. Note that the inlet $\mathrm{O}_{3}$ concentration in $\mathrm{O}_{3} / \mathrm{MnO}_{2}$-impregnated GAC is consistent with the photogenerated $\mathrm{O}_{3}$ from HFDEL.

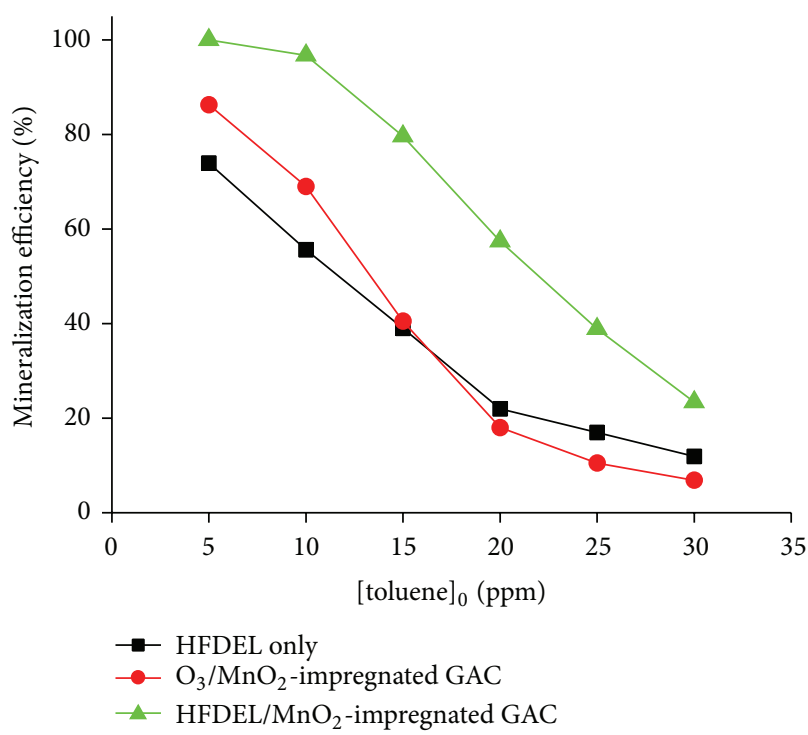

(a)

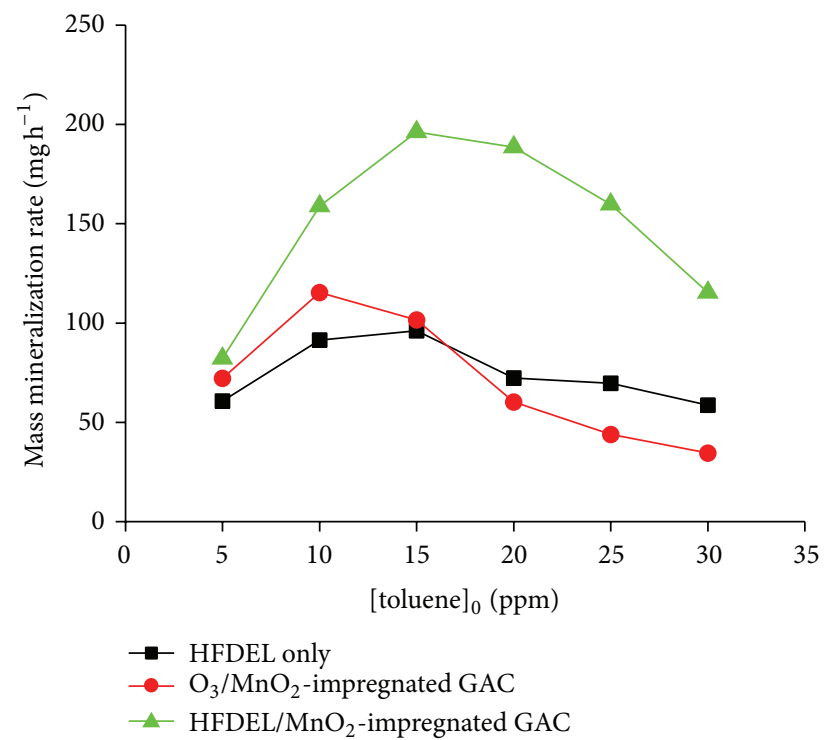

(b)

FIGURE 7: (a) Mineralization efficiency and (b) mass mineralization rate of toluene as a function of inlet toluene concentration by HFDEL only, $\mathrm{O}_{3} / \mathrm{MnO}_{2}$-impregnated GAC, and HFDEL/ $\mathrm{MnO}_{2}$-impregnated GAC, respectively. Note that the inlet $\mathrm{O}_{3}$ concentration in $\mathrm{O}_{3} / \mathrm{MnO}_{2}$ impregnated GAC is consistent with the photogenerated $\mathrm{O}_{3}$ from HFDEL.

the formation of intermediates during the photolysis process which are subjected to be mineralized by $\mathrm{HO}^{\circ}$ and $\mathrm{O}^{\circ}$ formed during $\mathrm{O}_{3}$ decomposition over $\mathrm{MnO}_{2}$-impregnated GAC compared to the original toluene [22].

Figures $6(\mathrm{~b})$ and $7(\mathrm{~b})$ demonstrate the removal and mineralization mass rate of toluene as a function of inlet toluene concentration from 5 to $30 \mathrm{ppm}$, respectively. The mass rates of toluene decomposition and mineralization by
HFDEL, $\mathrm{MnO}_{2}$-impregnated $\mathrm{GAC} / \mathrm{O}_{3}$, and HFDEL/MnO${ }_{2}$ impregnated GAC followed a similar profile which increased initially followed by a decrease with an increase in the inlet toluene (Figures 5(b) and 6(b)). During the photolysis process, $\mathrm{O}^{*}$ and $\mathrm{HO}^{\circ}$ formed via the absorbance of $h v(\lambda<$ $200 \mathrm{~nm}$ ) by $\mathrm{O}_{2}$ and $\mathrm{H}_{2} \mathrm{O}$, respectively (see (1) and (2)), are sufficient for low concentration of inlet toluene and thus the removal and mineralization mass rate increases with the inlet 
toluene concentration. With the inlet toluene concentration approaching to a certain concentration, however, toluene starts to compete with $\mathrm{O}_{2}$ and $\mathrm{H}_{2} \mathrm{O}$ to consume UV light at $185 \mathrm{~nm}$, resulting in a lower production rate of $\mathrm{O}^{\circ}$ and $\mathrm{HO}^{\circ}$. Although the direct photolysis of toluene by UV light at $185 \mathrm{~nm}$ can occur, the conversion rate of toluene by direct photolysis is much lower than that by $\mathrm{O}^{\circ}$ and $\mathrm{HO}^{\circ}$, respectively [17], thus resulting in a decrease in the removal and mineralization mass rate with a further increase in the inlet toluene concentration. For the catalyzed ozonation process $\left(\mathrm{MnO}_{2}\right.$-impregnated $\left.\mathrm{GAC} / \mathrm{O}_{3}\right)$, a decrease in the removal and mineralization mass rate of toluene with a further increase in the inlet toluene concentration was due to the decrease in the inlet $\mathrm{O}_{3}$ concentration with increasing in the inlet toluene concentration as the inlet $\mathrm{O}_{3}$ concentration in this study needs to be consistent with the photogenerated $\mathrm{O}_{3}$ concentration (Figure 2). For the low concentration of inlet toluene, an increase in removal and mineralization mass rate with the inlet toluene concentration can be observed since the high concentration of inlet $\mathrm{O}_{3}$ combined with $\mathrm{MnO}_{2}$-impregnated GAC results in the sufficient amount of $\mathrm{O}^{\circ}$ and $\mathrm{HO}^{\circ}$ for decomposition of toluene.

\section{Discussion}

In this study, we have shown that the removal efficiency of toluene using HFDEL depends on the inlet toluene concentration and the combination of $\mathrm{MnO}_{2}$-impregnated GAC with HFDEL can not only eliminate the residual $\mathrm{O}_{3}$ but also enhance the removal of toluene. More importantly, the synergistic effects of $\mathrm{HFDEL} / \mathrm{MnO}_{2}$-impregnated GAC on the mineralization of toluene have also been confirmed, showing the intermediates formed during the photolysis process are prone to be mineralized by the following $\mathrm{MnO}_{2}$-impregnated GAC catalyzed ozonation process. Possible mechanisms for the removal of toluene by $\mathrm{UV} / \mathrm{O}_{3} / \mathrm{MnO}_{2}$-impregnated GAC will be discussed in this section.

Under oxygen environment, the photo energy of VUV light at $185 \mathrm{~nm}$ produced by HFDEL is capable of destroying the bond of $\mathrm{O}=\mathrm{O}\left(491 \mathrm{~kJ} \mathrm{~mol}^{-1}\right)$, resulting in formation of $\mathrm{O}^{\circ}$ (see (1)) with a subsequent generation of $\mathrm{HO}^{\circ}$ and $\mathrm{O}_{3}$ (see (2) and (3)) $[29,30]$. Photogenerated $\mathrm{O}_{3}$ can efficiently be decomposed into $\mathrm{O}^{\circ}$ by UV irradiation (see (4)) and $\mathrm{O}^{\circ}$ can further react with $\mathrm{H}_{2} \mathrm{O}$ and $\mathrm{O}_{3}$ to generate $\mathrm{HO}^{\circ}$, respectively (see (2) and (5)) [31, 32]:

$$
\begin{gathered}
\mathrm{O}_{3}+h v(\lambda<254 \mathrm{~nm}) \longrightarrow \mathrm{O}^{\bullet}+\mathrm{O}_{2} \\
\mathrm{H}_{2} \mathrm{O}+\mathrm{O}_{3} \longrightarrow 2 \mathrm{HO}^{\bullet}+\mathrm{O}_{2}
\end{gathered}
$$

For $\mathrm{O}_{3}$ decomposition over the layer of $\mathrm{MnO}_{2}$-impregnated GAC, $\mathrm{O}_{3}$ can be also decomposed to form $\mathrm{O}^{\circ}$ on the active sites of $\mathrm{MnO}_{2}$-impregnated GAC surface (see (6)) and $\mathrm{O}^{\circ}$ can further react with $\mathrm{H}_{2} \mathrm{O}$ and $\mathrm{O}_{3}$ to generate $\mathrm{HO}^{\circ}$, respectively (see (2) and (5)) [17]:

$$
\mathrm{O}_{3}+* \longrightarrow \mathrm{O}^{\bullet}+\mathrm{O}_{2}
$$

where ${ }^{*}$ represents active sites on $\mathrm{MnO}_{2}$-impregnated GAC surface. Due to the limited direct photolysis of toluene by
VUV at $185 \mathrm{~nm}$, the primary pathway of toluene oxidation was the $\mathrm{H}$-abstraction from the methyl group by $\mathrm{HO}^{\circ}$ and $\mathrm{O}^{\circ}$, resulting in two pathways of toluene destruction in the $\mathrm{UV} / \mathrm{O}_{3} / \mathrm{MnO}_{2}$-impregnated GAC process.

The primary pathway of toluene oxidation by $\mathrm{HO}^{\bullet} / \mathrm{O}^{\bullet}$ was the $\mathrm{H}$-abstraction from the methyl group, resulting in the production of a benzyl radical and then the formation of benzyl alcohol and/or benzaldehyde [22], which were further attacked by $\mathrm{HO}^{\circ} / \mathrm{O}^{\bullet}$ leading to benzoic acid followed by the opening of the aromatic ring [33-35]. The compounds generated after the ring opening were substances with low molecular mass, such as formic acid, acetic acid, and $\mathrm{CO}$, with a subsequent formation of harmless $\mathrm{CO}_{2}$ and $\mathrm{H}_{2} \mathrm{O}$ by the attack of $\mathrm{HO}^{\circ} / \mathrm{O}^{\bullet}$. In our study, benzyl alcohol and benzaldehyde dimethyl acetal (BDA) as intermediates were detected by GC-MS analysis (Figure SM5). The presence of $\mathrm{BDA}$, the product of aldol condensation of benzaldehyde and methanol under acidic conditions, suggests that benzaldehyde is formed during the photolysis of toluene. Due to the lack of detection of benzoic acid, the acidic environment for the formation of BDA could be attributed to the formation of low molecular-weight acid (e.g., formic acid and acetic acid). The low boiling point of these small organic acids leads to no direct evidence to confirm their presence by GCMS. In summary, it can be proposed that the intermediates including benzyl alcohol and benzaldehyde are produced from the HFDEL system followed by the direct opening of the aromatic ring without formation of benzoic acid by the attack of $\mathrm{HO}^{\circ} / \mathrm{O}^{\circ}$. Compared to the original toluene compounds, these intermediates are more subjected to be decomposed to small molecules followed by the formation of $\mathrm{CO}_{2}$ and $\mathrm{H}_{2} \mathrm{O}$ via the subsequent $\mathrm{O}_{3} / \mathrm{MnO}_{2}$-impregnated $\mathrm{GAC}$ process, resulting in the synergistic mineralization of toluene using the $\mathrm{HFDEL} / \mathrm{MnO}_{2}$-impregnated GAC process.

\section{Conclusion}

The destruction of low concentration of toluene (0-30 ppm) has been studied under the advanced photooxidation processes by the combination of self-made HFDEL with $\mathrm{MnO}_{2}$ impregnated GAC catalyst. The conclusions are as follow:

(1) The concentration of photogenerated $\mathrm{O}_{3}$ from HFDEL decreased from 130 to $41 \mathrm{ppm}$ with an increase in the inlet toluene concentration from 0 to $30 \mathrm{ppm}$.

(2) The efficiency of decomposition of toluene by HFDEL decreased from 90 to $46 \%$ as the inlet toluene concentration increases from 5 to $30 \mathrm{ppm}$. The introduction of $\mathrm{MnO}_{2}$-impregnated GAC catalyst is not only to eliminate the residual $\mathrm{O}_{3}(41-130 \mathrm{ppm})$ completely but also to enhance the decomposition of toluene by $\sim 10 \%$. (The mass loading of $\mathrm{MnO}_{2}$ and the depth of GAC layer were $5 \%$ and $4.0 \mathrm{~cm}$, resp.)

(3) Active oxygen and hydroxyl radicals generated from $\mathrm{HFDEL} / \mathrm{MnO}_{2}$-impregnated GAC system played a key role in the decomposition of toluene process. The intermediates formed by photolysis are more 
prone to be mineralized by the subsequent $\mathrm{MnO}_{2}-$ impregnated GAC catalyst compared to the original toluene, resulting in synergistic mineralization of toluene by $\mathrm{HFDEL} / \mathrm{MnO}_{2}$-impregnated GAC system.

In summary, the combination of HFDEL and $\mathrm{MnO}_{2}-$ impregnated GAC efficiently enhances the toluene destruction process, eliminates the residual $\mathrm{O}_{3}$, and, more importantly, fulfills the synergistic mineralization of toluene, demonstrating that HFDEL/ $\mathrm{MnO}_{2}$-impregnated GAC system will be a promising air-cleaning technology for contamination of lower concentration of VOCs.

\section{Conflict of Interests}

The authors declare that there is no conflict of interests regarding the publication of this paper.

\section{Acknowledgments}

This work was supported by the National Natural Science Foundation of China (Grant no. 51178135) and China Postdoctoral Science Foundation (Grant no. 2014M560267).

\section{References}

[1] L. Zou, Y. Luo, M. Hooper, and E. Hu, "Removal of VOCs by photocatalysis process using adsorption enhanced $\mathrm{TiO}_{2}$ $\mathrm{SiO}_{2}$ catalyst," Chemical Engineering and Processing: Process Intensification, vol. 45, no. 11, pp. 959-964, 2006.

[2] Y. M. Kim, S. Harrad, and R. M. Harrison, "Concentrations and sources of VOCs in urban domestic and public microenvironments," Environmental Science and Technology, vol. 35, no. 6, pp. 997-1004, 2001.

[3] J. Peral, X. Domenech, and D. F. Ollis, "Heterogeneous photocatalysis for purification, decontamination and deodorization of air," Journal of Chemical Technology and Biotechnology, vol. 70, pp. 117-140, 1997.

[4] T. X. Liu, X. Z. Li, and F. B. $\mathrm{Li}$, "AgNO ${ }_{3}$-induced photocatalytic degradation of odorous methyl mercaptan in gaseous phase: Mechanism of chemisorption and photocatalytic reaction," Environmental Science and Technology, vol. 42, no. 12, pp. 45404545, 2008.

[5] T.-X. Liu, F.-B. Li, and X.-Z. Li, "Effects of peptizing conditions on nanometer properties and photocatalytic activity of $\mathrm{TiO}_{2}$ hydrosols prepared by $\mathrm{H}_{2} \mathrm{TiO}_{3}$," Journal of Hazardous Materials, vol. 155, no. 1-2, pp. 90-99, 2008.

[6] I. E. Den Besten and J. W. Tracy, "Electrodelessly discharged photochemical lamps," Journal of Chemical Education, vol. 50, no. 4, p. 303, 1973.

[7] S. Iwaguch, K. Matsumura, Y. Tokuoka, S. Wakui, and N. Kawashima, "Sterilization system using microwave and UV light," Colloids and Surfaces B: Biointerfaces, vol. 25, no. 4, pp. 299-304, 2002.

[8] I. Pandithas, K. Brown, A. I. Al-Shamma’, J. Lucas, and J. J. Lowke, "Biological applications of a low pressure microwave plasma UV lamp," in Proceedings of the 14th IEEE International Pulsed Power Conference (Ppc '03), vol. 1-2, pp. 1112-1115, 2003.

[9] S. Horikoshi, H. Hidaka, and N. Serpone, "Environmental remediation by an integrated microwave/UV-illumination method, 1. Microwave-assisted degradation of rhodamine-B dye in aqueous $\mathrm{TiO}_{2}$ dispersions," Environmental Science and Technology, vol. 36, no. 6, pp. 1357-1366, 2002.

[10] S. Horikoshi, H. Hidaka, and N. Serpone, "Environmental remediation by an integrated microwave/UV illumination technique. 3. A microwave-powered plasma light source and photoreactor to degrade pollutants in aqueous dispersions of $\mathrm{TiO}_{2}$ illuminated by the emitted UV/visible radiation," Environmental Science and Technology, vol. 36, no. 23, pp. 5229-5237, 2002.

[11] S. Horikoshi, H. Hidaka, and N. Serpone, "Environmental remediation by an integrated microwave/UV illumination technique VI. A simple modified domestic microwave oven integrating an electrodeless UV-Vis lamp to photodegrade environmental pollutants in aqueous media," Journal of Photochemistry and Photobiology A, vol. 161, no. 2-3, pp. 221-225, 2004.

[12] S. Horikoshi, F. Hojo, H. Hidaka, and N. Serpone, "Environmental remediation by an integrated microwave/UV illumination technique. 8. Fate of carboxylic acids, aldehydes, alkoxycarbonyl and phenolic substrates in a microwave radiation field in the presence of $\mathrm{TiO}_{2}$ particles under UV irradiation," Environmental Science and Technology, vol. 38, no. 7, pp. 21982208, 2004.

[13] P. Klan, J. Literak, and M. Hajek, "The electrodeless discharge lamp: a prospective tool for photochemistry," Journal of Photochemistry and Photobiology A, vol. 128, pp. 145-149, 1999.

[14] L.-Y. Xia, D.-H. Gu, J. Tan, W.-B. Dong, and H.-Q. Hou, "Photolysis of low concentration $\mathrm{H}_{2} \mathrm{~S}$ under UV/VUV irradiation emitted from microwave discharge electrodeless lamps," Chemosphere, vol. 71, no. 9, pp. 1774-1780, 2008.

[15] J. Xu, C. Li, P. Liu, D. He, J. Wang, and Q. Zhang, "Photolysis of low concentration $\mathrm{H}_{2} \mathrm{~S}$ under UV/VUV irradiation emitted from high frequency discharge electrodeless lamps," Chemosphere, vol. 109, pp. 202-207, 2014.

[16] P. M. Álvarez, J. P. Pocostales, and F. J. Beltrán, “Granular activated carbon promoted ozonation of a food-processing secondary effluent," Journal of Hazardous Materials, vol. 185, no. 2-3, pp. 776-783, 2011.

[17] J. Jeong, K. Sekiguchi, and K. Sakamoto, "Photochemical and photocatalytic degradation of gaseous toluene using shortwavelength UV irradiation with $\mathrm{TiO}_{2}$ catalyst: comparison of three UV sources," Chemosphere, vol. 57, no. 7, pp. 663-671, 2004.

[18] K.-P. Yu and G. W. M. Lee, "Decomposition of gas-phase toluene by the combination of ozone and photocatalytic oxidation process $\left(\mathrm{TiO}_{2} / \mathrm{UV}, \mathrm{TiO}_{2} / \mathrm{UV} / \mathrm{O}_{3}\right.$, and $\left.\mathrm{UV} / \mathrm{O}_{3}\right)$," Applied Catalysis B: Environmental, vol. 75, no. 1-2, pp. 29-38, 2007.

[19] P. Müller, P. Klán, and V. Ćrkva, “The electrodeless discharge lamp: A prospective tool for photochemistry Part 4: temperature- and envelope material-dependent emission characteristics," Journal of Photochemistry and Photobiology A: Chemistry, vol. 158, no. 1, pp. 1-5, 2003.

[20] E. J. Hart, K. Sehested, and J. Holcman, "Molar absorptivities of ultraviolet and visible bands of ozone in aqueous solutions," Analytical Chemistry, vol. 55, no. 1, pp. 46-49, 1983.

[21] H. Einaga and S. Futamura, "Catalytic oxidation of benzene with ozone over alumina-supported manganese oxides," Journal of Catalysis, vol. 227, no. 2, pp. 304-312, 2004.

[22] H. Huang and W. Li, "Destruction of toluene by ozoneenhanced photocatalysis: performance and mechanism," Applied Catalysis B: Environmental, vol. 102, no. 3-4, pp. 449-453, 2011. 
[23] B. Liu, A. Li, M. Xia, and Z. Zhu, "Preparation of manganese oxide supported on activated carbon and its application in catalytic ozonation of 4-chlorophenol," Advanced Materials Research, vol. 538-541, pp. 2285-2288, 2012.

[24] J. Hoigne and H. Bader, "Rate constants of reactions of ozone with organic and inorganic compounds in water, 1. Nondissociating organic compounds," Water Research, vol. 17, no. 2, pp. 173-183, 1983.

[25] L. M. Dorfman, I. A. Taub, and D. A. Harter, "Rate constants for the reaction of the hydroxyl radical with aromatic molecules," The Journal of Chemical Physics, vol. 41, no. 9, pp. 2954-2955, 1964.

[26] H. C. Christensen, K. Sehested, and E. J. Hart, "Formation of benzyl radicals by pulse radiolysis of toluene in aqueous solutions," The Journal of Physical Chemistry, vol. 77, no. 8, pp. 983-987, 1973.

[27] J. Ma and N. J. D. Graham, "Degradation of atrazine by manganese-catalysed ozonation: influence of humic substances," Water Research, vol. 33, no. 3, pp. 785-793, 1999.

[28] S. Futamura, A. Zhang, H. Einaga, and H. Kabashima, "Involvement of catalyst materials in nonthermal plasma chemical processing of hazardous air pollutants," Catalysis Today, vol. 72, no. 3-4, pp. 259-265, 2002.

[29] J. H. Seinfeld and I. Pandis, Atmospheric Chemistry and Physics: From Air Pollution to Climate Change, John Wiley \& Sons, 2nd edition, 2006.

[30] D. He, A. M. Jones, S. Garg, A. N. Pham, and T. D. Waite, "Silver nanoparticle-reactive oxygen species interactions: application of a charging-discharging model," Journal of Physical Chemistry C, vol. 115, no. 13, pp. 5461-5468, 2011.

[31] X. Huang, J. Yuan, J. Shi, and W. Shangguan, “Ozone-assisted photocatalytic oxidation of gaseous acetaldehyde on $\mathrm{TiO}_{2} / \mathrm{H}-$ ZSM-5 catalysts," Journal of Hazardous Materials, vol. 171, no. 1-3, pp. 827-832, 2009.

[32] M. Kogoma, Y. Miki, K. Tanaka, and K. Takahashi, "Highly efficient VOC decomposition using a complex system $(\mathrm{OH}$ radical, ozone-UV, and $\mathrm{TiO}_{2}$ )," Plasma Processes and Polymers, vol. 3, no. 9, pp. 727-733, 2006.

[33] M. Sleiman, P. Conchon, C. Ferronato, and J. M. Chovelon, "Photocatalytic oxidation of toluene at indoor air levels (ppbv): towards a better assessment of conversion, reaction intermediates and mineralization," Applied Catalysis B: Environmental, vol. 86, no. 3-4, pp. 159-165, 2009.

[34] T. J. Frankcombe and S. C. Smith, "OH-initiated oxidation of toluene. 1. Quantum chemistry investigation of the reaction path," Journal of Physical Chemistry A, vol. 111, no. 19, pp. 36863690, 2007.

[35] T. J. Frankcombe and S. C. Smith, "OH-initiated oxidation of toluene. 2. Master equation simulation of toluene oxide isomerization," The Journal of Physical Chemistry A, vol. 111, no. 19, pp. 3691-3696, 2007. 

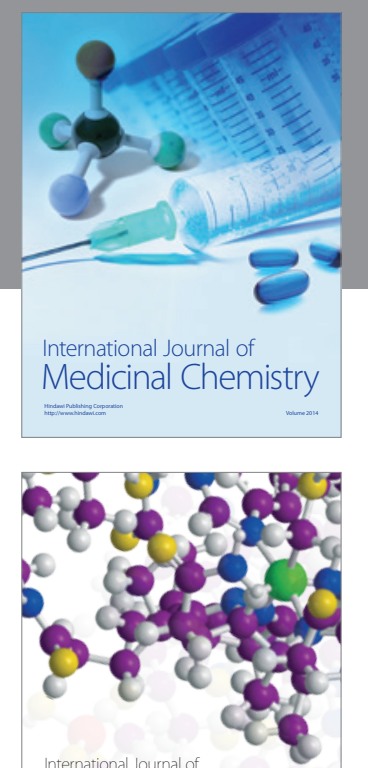

\section{Carbohydrate} Chemistry

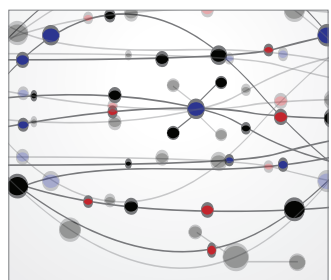

The Scientific World Journal
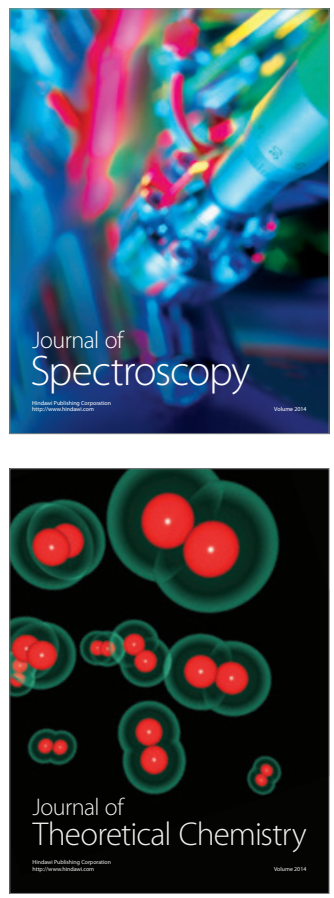
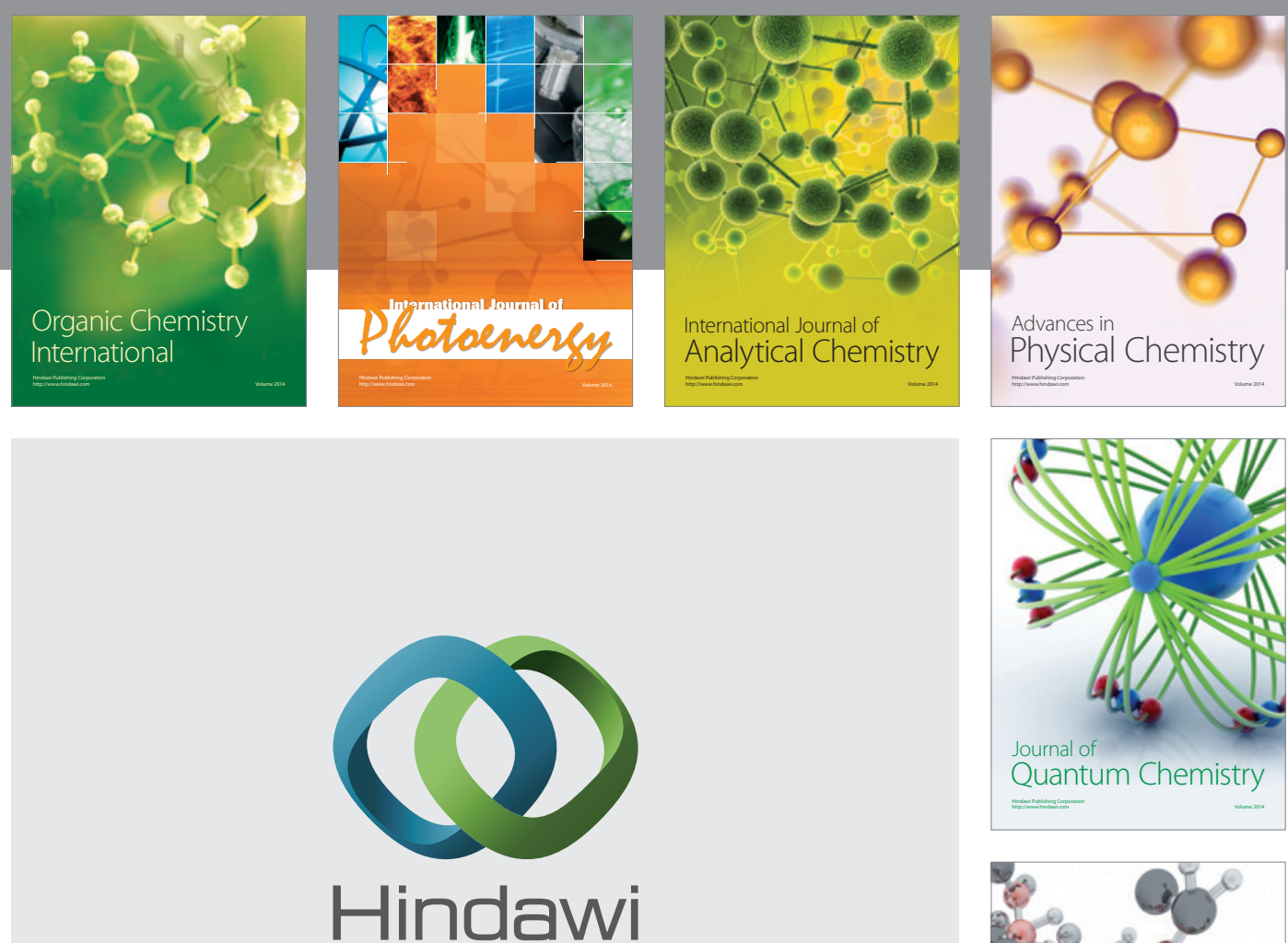

Submit your manuscripts at

http://www.hindawi.com

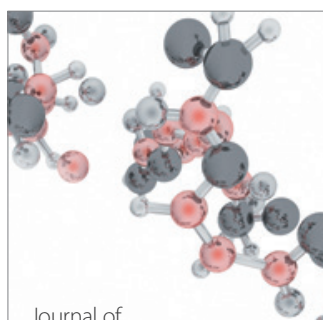

Analytical Methods

in Chemistry

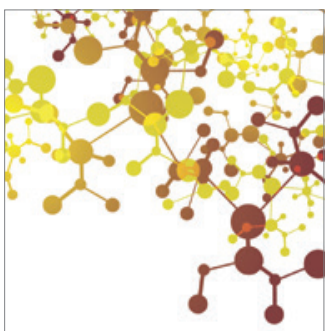

Journal of

Applied Chemistry

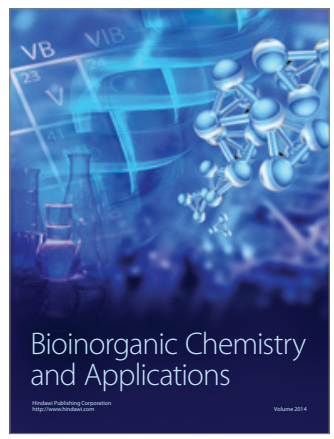

Inorganic Chemistry
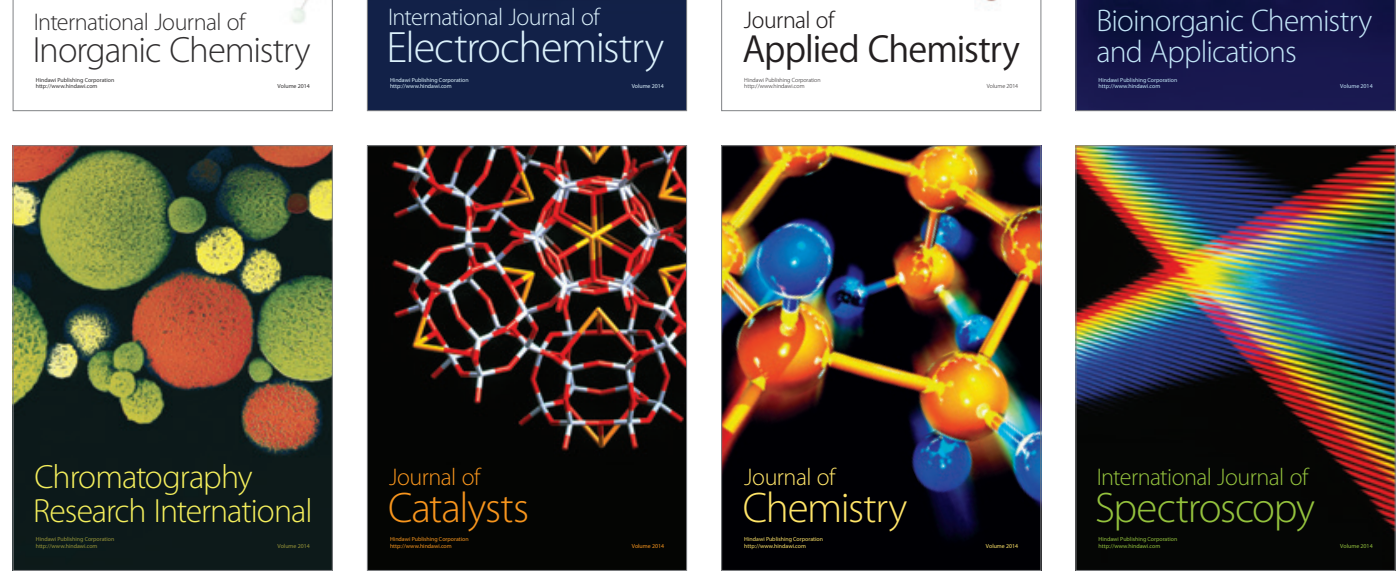